Research article

Open Access

\title{
Brain-derived neurotrophic factor and its receptor in the human and the sand rat intervertebral disc
}

\author{
Helen E Gruber ${ }^{1}$, Jane A Ingram ${ }^{1}$, Gretchen Hoelscher ${ }^{1}$, Natalia Zinchenko ${ }^{1}$, H James Norton ${ }^{2}$ and \\ Edward N Hanley Jr ${ }^{1}$
}

\author{
1Department of Orthopaedic Surgery, Carolinas Medical Center, PO Box 32861, Charlotte, NC 28232, USA \\ 2Department of Biostatistics, Carolinas Medical Center, PO Box 32861, Charlotte, NC 28232, USA \\ Corresponding author: Helen E Gruber, helen.gruber@carolinashealthcare.org \\ Received: 10 Apr 2008 Revisions requested: 2 Jun 2008 Revisions received: 17 Jun 2008 Accepted: 17 Jul 2008 Published: 17 Jul 2008 \\ Arthritis Research \& Therapy 2008, 10:R82 (doi:10.1186/ar2456) \\ This article is online at: http://arthritis-research.com/content/10/4/R82 \\ (c) 2008 Gruber et al.; licensee BioMed Central Ltd. \\ This is an open access article distributed under the terms of the Creative Commons Attribution License (http://creativecommons.org/licenses/by/2.0), \\ which permits unrestricted use, distribution, and reproduction in any medium, provided the original work is properly cited.
}

\begin{abstract}
Introduction Brain-derived neurotrophic factor (BDNF) was first identified in the intervertebral disc (IVD) when its molecular upregulation was observed in sections of nucleus pulposus cultured under conditions of increased osmolarity. BDNF is now known to be involved in a number of biologic functions, including regulation of differentiation/survival of sensory neurons, regulation of nociceptive function and central pain modulation, and modulation of inflammatory pain hypersensitivity. In addition, more recent investigations show that BDNF can induce the recruitment of endothelial cells and the formation of vascular structures. The objectives of the present study were to use immunocytochemistry to determine the distribution of BDNF and its receptor (BDNF-tropomyosine receptor kinase $B$ ) in the human IVD, and to test for gene expression of BDNF and its receptor in cultured human annulus fibrosus cells.
\end{abstract}

Methods We studied immunohistochemical localization of BDNF and its receptor in the human annulus, quantified the percentage of outer annulus and inner annulus cells and nucleus cells positive for BDNF immunolocalization, and studied the gene expression of BDNF and its receptor using microarray analysis.

Results The percentage (mean \pm standard error of the mean) of cells positive for BDNF localization was significantly greater in the outer annulus $(32.3 \pm 2.7 \%, \mathrm{n}=22)$ compared with either the inner annulus $(8.1 \pm 1.5 \%, \mathrm{n}=6)$ or the nucleus $(10.4 \pm$ $2.8 \%, \mathrm{n}=3)(P<0.0001)$. BDNF-receptor immunolocalization showed a pattern similar to that of BDNF, but was not quantitatively assessed. BDNF gene expression levels from cultured annulus cells showed a significant positive correlation with increasing levels of IVD degeneration $(P=0.011)$.

Conclusion These findings provide data on the presence of BDNF and its receptor in the human IVD at the translational level, and on the expression of BDNF and its receptor by cultured human annulus cells. Our findings point to the need for further studies to define the role of BDNF in the human IVD and to investigate regulatory events within the disc that control the expression of BDNF and its receptor.

\section{Introduction}

Brain-derived neurotrophic factor (BDNF) was first identified in the intervertebral disc (IVD) when its molecular upregulation was observed in sections of nucleus pulposus cultured under conditions of increased osmolarity by Boyd and colleagues [1]. BDNF is now known to be involved in a number of biologic functions, including regulation of differentiation/survival of sensory neurons, regulation of nociceptive function and central pain modulation, and modulation of inflammatory pain hypersensitivity.
Nerves grow into tissues in response to signaling molecules called neurotrophins, which are involved in the survival, differentiation, migration and outgrowth of neurons. We now know that neurotrophins are expressed in non-neuronal tissues, including the IVD [2-4]. Gigante and colleagues recently reported the presence of nerve growth factor (NGF) mRNA, the high-affinity tyrosine kinase $A$ receptor and the low-affinity p75 receptor in rounded cells in the disc annulus and nucleus pulposus [5]. NGF and its receptors tyrosine kinase $A$ and p75 are expressed not only in the developing nervous system, but also in the mature adult nervous system - where they are

$\overline{\mathrm{BDNF}}=$ brain-derived neurotrophic factor; IVD = intervertebral disc; IL = interleukin; NGF = nerve growth factor; TNF = tumor necrosis factor. 
particularly important because of their association of primary nociceptive neurons. The recent review by Mendell and colleagues points out that in adults NGF acts as an important intermediate in pain, contributing to peripheral and central sensitization [6].

One other neurotrophin has previously been studied in the IVD. Abe and colleagues have reported on the expression of NGF by human IVD cells in control disc tissue in vivo and in vitro in cells from control IVDs using immunocytochemistry [7]. NGF was found to be high in the outer annulus and in herniated disc tissue. Abe and colleagues' work also demonstrated that the proinflammatory cytokines IL-1 and TNF $\alpha$ had stimulatory effects on NGF. These authors suggested that such actions may play a role in nerve sprouting into the IVD, and may be associated with discogenic pain.

Ohtori and colleagues have reported on the presence of BDNF in dorsal root ganglion neurons innervating lumbar discs in the rat [8]. Supraspinal BDNF-tyrosine kinase receptor $B$ signaling is now known to represent a mechanism underlying the development of persistent pain $[9,10]$.

Another important role for BDNF involves more recent advances in our understanding of BDNF function. The interesting studies by Kermani and colleagues have documented the ability of BDNF to promote revascularization via endothelial cells and hematopoietic progenitors [11]. These investigators suggest their work with skeletal muscle and heart indicates that the signaling pathway involving BDNF and its receptor may also be active in modulation of angiogenesis in specific organs in the adult. In light of the avascular status of the adult IVD, this role merits future research.

Because of the significance of BDNF in the IVD, our objectives in the present work were to use immunocytochemistry to determine the distribution of BDNF and its receptor in the human IVD, and to test for gene expression of BDNF and its receptor in cultured human annulus fibrosus cells.

\section{Materials and methods Clinical study population}

The experimental study of human IVD specimens was approved prospectively by the authors' Human Subjects Institutional Review Board (protocol number 08-04-09E). The need for informed consent was waived (since surgical IVD tissue is routinely discarded at our institution). Surgeries for disc degeneration are routine clinical practice in our hospital. The Thompson grading system is used to score IVD degeneration over the spectrum of stages from Thompson grade I (a healthy disc) to discs with advanced degeneration (Thompson grade V) [12].

Patient specimens were derived from surgical disc procedures performed on individuals with herniated discs and with degenerative disc disease. Surgical specimens were transported to the laboratory ( $<30 \mathrm{~min}$ after surgical removal) in sterile tissue culture medium and were placed in $10 \%$ neutral buffered formalin for no longer than 24 hours. Care was taken to remove all granulation tissue and to sample only IVD tissue. Donor disc specimens were obtained via the National Cancer Institute Cooperative Human Tissue Network; they were shipped overnight to the laboratory in sterile tissue culture medium and were processed as described below. Procurement of specimens from the Cooperative Human Tissue Network was also approved via our Institutional Review Board. Specimens were embedded in paraffin without decalcification.

\section{Sand rat intervertebral disc tissue}

Animal studies were performed following approval by the Institutional Animal Care and Use Committee. Psammomys obesus, the sand rat, is used in our laboratory for studies of IVD degeneration. Colony housing and animal diet descriptions have been published previously $[13,14]$.

Spines from seven animals were used in the present study of the immunolocalization of BDNF. The spines were removed immediately following animal euthanization, and the IVDs were harvested, fixed in 10\% neutral buffered formalin, decalcified, and embedded in paraffin so that en face sections of the disc could be obtained. Sections were processed for immunohistochemical localization of BDNF as described below.

\section{BDNF immunohistochemistry performed on human intervertebral disc tissue and determination of the percentage of positive cells}

Paraffin sections were cut at $4 \mu \mathrm{m}$, collected on PLUS slides (Allegiance, McGaw Park, IL, USA), dried at $60^{\circ} \mathrm{C}$, deparaffinized in xylene (Allegiance) and rehydrated through graded alcohols (AAPER, Shelbyville, KY, USA) to distilled water. Antigen retrieval was performed using Dako Target Retrieval Solution, pH 6.0 (Dako, Carpenteria, CA, USA) for 20 minutes at $95^{\circ} \mathrm{C}$ followed by cooling for 20 minutes. The remainder of the procedure was performed using the Dako Autostainer Plus (Dako) automated stainer. Endogenous peroxidase was blocked using $3 \% \mathrm{H}_{2} \mathrm{O}_{2}$ (Humco, Texarcana, TX, USA). Slides were incubated for 1 hour with antihuman BDNF (clone number 35928; R\&D Systems, Minneapolis, MN, USA) at a 1:20 dilution. Mouse IgG (Dako) was used as a negative control. The secondary antibody was Dako LSAB2 biotinylated Link for HRP/AP (Dako) for 10 minutes followed by peroxidase-conjugated streptavidin (Dako) for 10 minutes and DAB (Dako) for 5 minutes. Slides were removed from the stainer, rinsed in water, counterstained with light green, dehydrated, cleared and mounted with resinous mounting media.

The proportion of cells positive for BDNF localization was determined for the outer annulus, the inner annulus and the nucleus. For quantitation, the average total numbers of cells scored were as follows (mean \pm standard deviation): outer 
annulus, $387 \pm 110(\mathrm{n}=22)$; inner annulus, $390 \pm 154(\mathrm{n}=$ $6)$, and nucleus, $331 \pm 43(n=4)$.

\section{BDNF immunohistochemistry performed on sand rat intervertebral disc tissue}

Immunohistochemistry was performed as described above with the following exceptions. The antibodies were biotinylated using the Dako ARK Kit (Dako). Sections were incubated with streptavidin peroxidase (Dako ARK Kit) for 15 minutes at room temperature and were then incubated in $D A B$ (Dako) for 5 minutes. Rinses were performed between the application of each reagent on the AutostainerPlus using Trisbuffered saline containing Tween-20 (Dako). Slides were removed from the stainer, rinsed in water, counterstained with $0.03 \%$ light green (Polysciences, Warrington, PA, USA), dehydrated cleared and mounted with Cytoseal XYL (RichardAllan Scientific, Kalamazoo, MI, USA).

\section{BDNF-receptor immunolocalization}

Embedding, sectioning and blocking endogenous peroxidase using $3 \% \mathrm{H}_{2} \mathrm{O}_{2}$ were performed as described above. Slides were then incubated for 1 hour with rabbit antibody to tyrosine kinase receptor $B$ (BDNF receptor, batch number Rb68010906-WS; Biosensis, Flagstaff Hill, Australia) at a 1:500 dilution. Universal negative control rabbit (Dako) was used as a negative control. The secondary antibody was Dako LSAB2 biotinylated Link for HRP/AP (Dako) for 10 minutes followed by peroxidase-conjugated streptavidin (Dako) for 10 minutes and DAB (Dako) for 5 minutes. Slides were removed from the stainer, rinsed in water, counterstained with light green, dehydrated, cleared and mounted with resinous mounting media.

\section{Human intervertebral disc cell culture}

Annulus cells were grown in monolayer culture (seeded at 150,000 cells/well) on a Lab-Tek ${ }^{\circledR}$ Chamber Slide ${ }^{\mathrm{TM}}$ (Nunc, Napierville, IL, USA) or in three dimensions in a collagen sponge as previously described $[15,16]$.

\section{Gene expression studies}

Human IVD tissue, annulus cells in a monolayer, and annulus cells in three-dimensional culture were assayed for gene expression using the Affymetrix microarray system (Affymetrix, Santa Clara, CA 95051, USA). Harvested cells were placed in extraction buffer from the PicoPure RNA Isolation Kit (Arcturus, Mountainview, CA, USA), and total RNA was extracted from the tissue using the PicoPure RNA Isolation Kit following the manufacturer's instructions, were reverse transcribed to double-stranded cDNA, were subjected to two rounds of transcription, and were hybridized to the DNA microarray in the Affymetrix Fluidics Station 400 (Affymetrix, Santa Clara, CA 95051, USA). Affymetrix human U133 X3P arrays were used (Affymetrix, Santa Clara, CA 95051, USA). The GeneChip ${ }^{\circledR}$ Operating Software Affymetrix GeneChip Operating System (version 1.2; Affymetrix, Santa Clara, CA 95051, USA) was used for determining gene expression levels.

\section{Statistical analysis}

The statistical analysis utilized standard methods using SAS software (version 8.2; SAS Institute, Cary, NC, USA). Methods used included unpaired $t$ tests and Spearman's correlation statistics. $P<0.05$ was considered statistically significant. Data are expressed as the mean \pm standard error of the mean, or mean \pm standard deviation where noted.

\section{Results}

Immunohistochemical specimens used in the localization of BDNF and of the BDNF receptor are described in Table 1. Thirty-one IVDs from 22 subjects were evaluated; three subjects were control donors, and 19 subjects were patients undergoing disc surgery. The study design included discs within each of the Thompson grade classifications. Since the majority of the surgical specimens we obtain come from grade III and grade IV discs, there were fewer grade I and grade V discs in the present study.

\section{BDNF immunolocalization}

Immunolocalization of BDNF was greatest in the outer annulus (Figure 1a,b). Localization of positive cells next to negative cells was also observed in the outer annulus, the inner annulus and the nucleus (Figure 1c to 1e; Figure $1 \mathrm{f}$ is a negative control). Positive and negative cells were present within small clusters (Figure 1e). Annulus cells encapsulated by the extracellular matrix also showed positive localization (Figure 2).

The proportions of BDNF-positive cells were quantitatively determined for the outer annulus, the inner annulus and the nucleus pulposus. The outer annulus contained an average of $32.3 \pm 2.7 \%(n=22)$ (mean \pm standard error of the mean) cells positive for BDNF, a significantly greater level than that present in the inner annulus $(8.1 \pm 1.5 \%, \mathrm{n}=6)$ or in the nucleus $(10.4 \pm 2.8 \%, n=4)(P \leq 0.01)$ (Figure 3$)$. When data for the outer annulus were assessed based on the degenerative stage of the IVD (Thompson grade), no significant relationship was present (Figure 4).

Sand rat lumbar IVDs sectioned en face showed a similar pattern of localization of BDNF. The greatest number of positive cells was present in the outer annulus, with fewer positive cells as one viewed the inner annulus (Figure 5).

\section{BDNF-receptor immunolocalization}

Localization patterns were similar for the BDNF receptor to that seen for BDNF. Both positive cells and negative cells were present, with the greatest number of positive cells present in the outer annulus (Figure 6). Positive cells were occasionally present in the nucleus in human specimens. Sand rat lumbar IVDs showed a similar localization pattern, with a larger proportion of positive cells in the outer annulus compared with the inner annulus or the nucleus (Figure 7). 
Table 1

Demographic features of specimens studied for immunocytochemical localization of brain-derived neurotrophic factor and of its receptor

\begin{tabular}{|c|c|c|c|c|c|}
\hline Subject number & Site & Thompson score & Age (years), gender & Other information & Herniated? \\
\hline \multirow[t]{2}{*}{1} & L4 to L5: OA, IA, nuc & 1.5 & 45, female & $\begin{array}{l}\text { Cooperative Human Tissue Network } \\
\text { - unknown cause of death }\end{array}$ & - \\
\hline & L3 to L4: OA, IA, nuc & 2 & & & - \\
\hline 2 & L4 to L5 & 2 & 35, female & Surgical specimen & No \\
\hline 3 & L4 to L5 & 2 & 32, female & Surgical specimen & Yes \\
\hline 4 & L5 to $\mathrm{S} 1$ & 2 & 21, male & Surgical specimen & Yes \\
\hline 5 & L4 to L5 & 2 & 44, female & Surgical specimen & Yes \\
\hline 6 & L4 to L5 & 2 & 37, female & Surgical specimen & Yes \\
\hline 7 & L4 to L5: OA, IA, nuc & 2.5 & 40, male & $\begin{array}{l}\text { Cooperative Human Tissue Network } \\
\text { - cause of death, myocardial infarct }\end{array}$ & - \\
\hline 8 & L4 to L5 & 3 & 46, female & Surgical specimen & No \\
\hline 9 & L3 to L4 & 3 & 53, male & Surgical specimen & Yes (recurrent) \\
\hline 10 & L4 to L5 & 3 & 53, male & Surgical specimen & No \\
\hline 11 & L4 to L5, L5 to S1 & 3 & 29, female & Surgical specimen & No \\
\hline 12 & L4 to L5 & 3 & 54 , male & Surgical specimen & Yes \\
\hline 13 & $\mathrm{~L} 2$ to $\mathrm{L} 3$ & 3 & 58, male & Surgical specimen & Yes \\
\hline 14 & L1 to $L 2: \mathrm{OA}, \mathrm{IA}$, nuc & 3 & 33, female & $\begin{array}{l}\text { Cooperative Human Tissue Network } \\
\text { - cause of death, pulmonary } \\
\text { embolism }\end{array}$ & - \\
\hline 14 & T12 to $L 1: O A, I A$, nuc & 3.5 & & & - \\
\hline 14 & L3 to L4: OA, IA, nuc & 4 & & & - \\
\hline 15 & $\mathrm{~L} 1$ to $\mathrm{L} 2, \mathrm{~L} 2$ to $\mathrm{L} 3, \mathrm{~L} 3$ to $\mathrm{L} 4$ & 4 & 59, female & Surgical specimen & No \\
\hline 16 & L4 to L5 & 4 & 39, female & Surgical specimen & Yes (recurrent) \\
\hline 17 & $\mathrm{~L} 5$ to $\mathrm{S} 1$ & 4 & 48, female & Surgical specimen & Yes (recurrent) \\
\hline 18 & $\begin{array}{l}\mathrm{L} 2 \text { to } \mathrm{L} 3, \mathrm{~L} 3 \text { to } L 4, \mathrm{~L} 4 \text { to } \mathrm{L} 5 \text {, } \\
\mathrm{L} 5 \text { to } \mathrm{S} 1\end{array}$ & 4 & 56 , female & Surgical specimen & No \\
\hline 19 & L4 to L5 & 4 & 19, male & Surgical specimen & No \\
\hline 20 & L3 to L4 & 4 & 78, male & Surgical specimen & Yes \\
\hline 21 & $\mathrm{~L} 5$ to $\mathrm{S} 1$ & 5 & 44, female & Surgical specimen & No \\
\hline 22 & L5 to $S 1$ & 5 & 39, male & Surgical specimen & No \\
\hline
\end{tabular}

IA, inner annulus; L, lumbar; nuc, nucleus; OA, outer annulus; L, lumbar.

\section{Gene expression of BDNF by annulus cells}

The final portion of the present study looked at gene expression of BDNF by human annulus cells cultured in monolayer and three dimensions. Annulus cells were all derived from surgical patients. This experiment utilized one grade II disc (patient aged 45 years), five grade III discs (mean patient age 38.6 years), and four grade IV discs (mean patient age 52.2 years). All cells were cultured for 10 days prior to cell harvest. Positive expression levels were observed in all specimens for BDNF (gene identifier NM 001709.1) per microarray analysis.
The BDNF gene expression levels correlated significantly and in a positive manner with the Thompson disc grade for the cell cultures $(P=0.011, r=0.72)$. When expression levels in grades II and grade III discs (the healthier discs in this evaluation) were pooled and compared with mean expression levels in grade IV discs, significantly higher expression was identified in the more degenerate IVDs $(P=0.037$; Figure 8$)$.

\section{Discussion}

The present study presents novel immunocytochemical data demonstrating the presence of BDNF and of BDNF receptor in the human outer annulus, inner annulus and nucleus pulpo- 
Figure 1
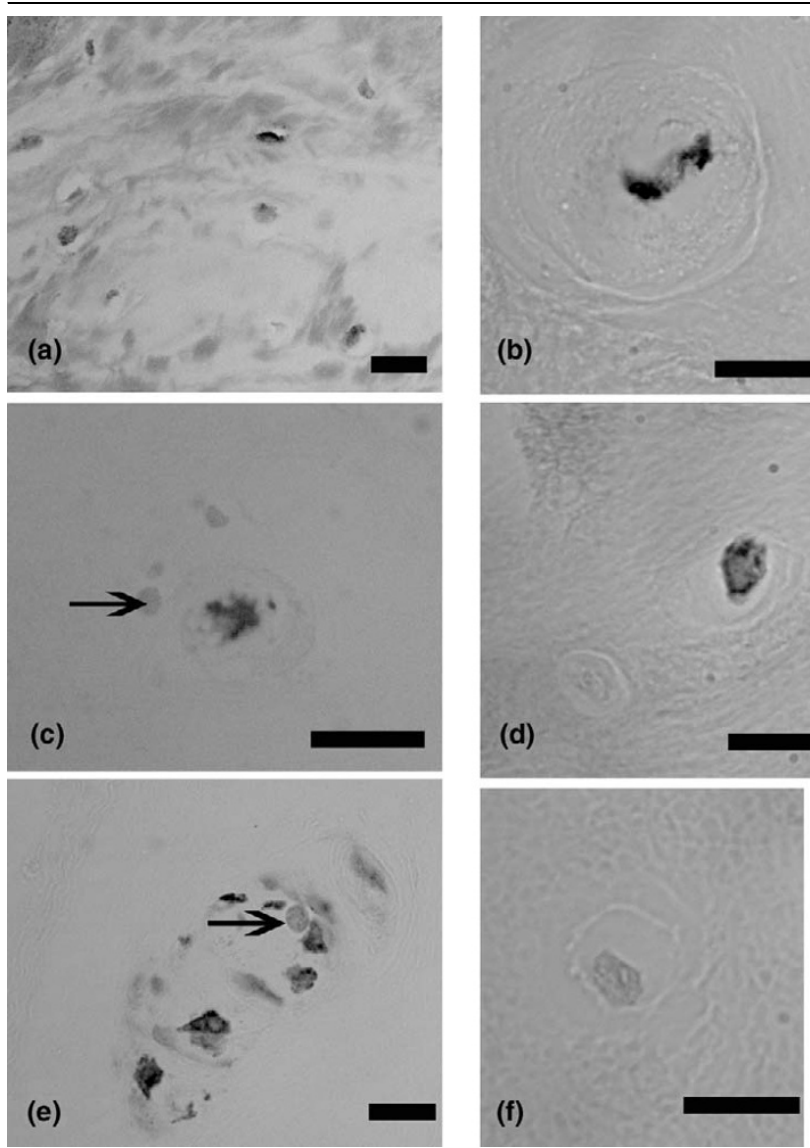

Immunolocalization of brain-derived neurotrophic factor in human intervertebral discs. (a) Outer annulus, subject number 14, L3 to L4. (b) Outer annulus, subject number 4, L1 to L2. (c) Nucleus, subject number 14, L3 to L4 (arrow marks nearby negative cell). (d) Outer annulus, subject number $4, \mathrm{~L} 1$ to $\mathrm{L} 2$ (note nearby cell that does not show localization). (e) Inner annulus, subject number 14, a cluster of cells (arrow marks one of the negative cells that lies near the positive cells). (f) Negative control. Bars: (a) $10 \mu \mathrm{m}$, (b) $0.1 \mu \mathrm{m}$, (c) $10 \mu \mathrm{m}$, (d) $10 \mu \mathrm{m},(\mathrm{e}) 10 \mu \mathrm{m},(\mathrm{f}) 10 \mu \mathrm{m}$.

sus. Quantitative assessment of the proportion of cells positive for BDNF localization showed significantly greater localization in the outer annulus compared with the inner annulus or the nucleus pulposus $(P \leq 0.01)$. Quantitative analysis was not performed for the BDNF receptor, but qualitatively its localization appeared to follow a similar pattern.

BDNF and the BDNF receptor were also found to be present in sand rat lumbar IVDs, and the immunolocalization pattern was similar to that seen in human IVDs but with more labeled cells present in the outer annulus. Inner annulus cell and nucleus cells in the human IVD were found to occasionally show positive immunolocalization, but at a significantly lower proportion. Although there was minimal background present in the animal tissues, it must be remembered that this portion of our study utilized antihuman antibodies, no biochemical analysis of the cross-reactivity of the sand rat substrates was car-
Figure 2

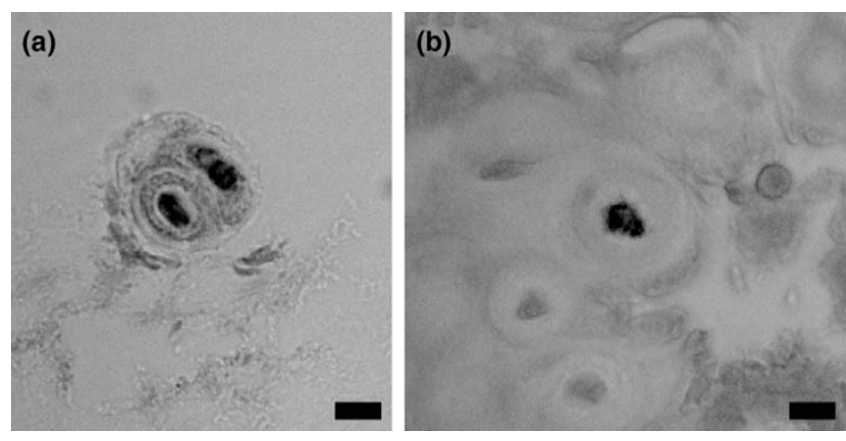

Immunolocalization of brain-derived neurotrophic factor in annulus cells with prominent encapsulating extracellular matrix. (a) Inner annulus, subject number 6, L4 to L5. (b) Inner annulus, subject number 12, L4 to L5. Bars $=10 \mu \mathrm{m}$.

ried out, and a danger of some false-positive reactivity with proteins in the sand rat IVD remains a concern that at present cannot be discounted.

Neurotrophins are beginning to be viewed as important agents in the IVD. Aoki and colleagues have suggested that NGFdependent neurons may be the nerve population responsible for discogenic pain based on findings from studies of disc degeneration in rats $[17,18]$. A study of human discs from subjects with low back pain performed by Freemont and colleagues identified a positive relationship between ingrowth of nonmyelinated, nociceptive nerves into the IVD and the production of nerve growth factor by nearby ingrowing blood vessels [19].

\section{Figure 3}

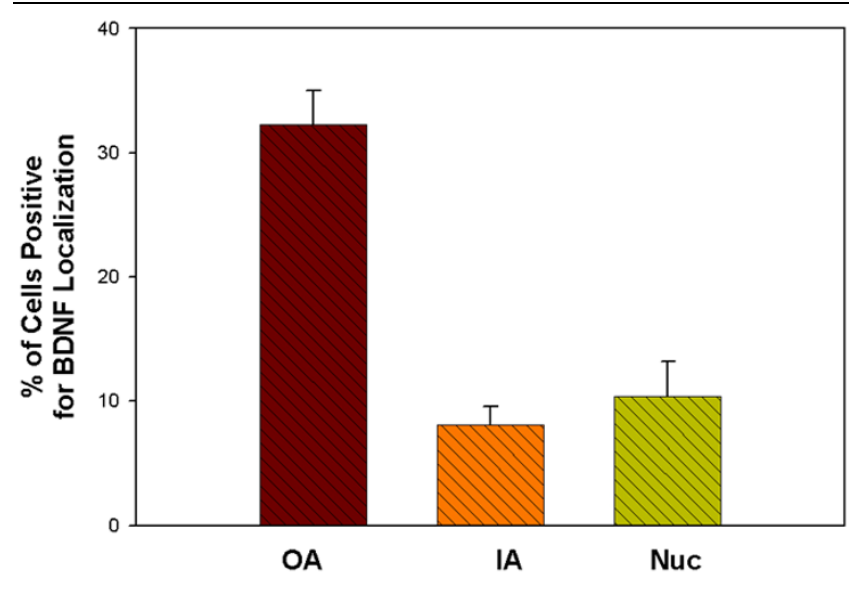

Cells positive for brain-derived neurotrophic factor localization. Mean percentages of cells positive for brain-derived neurotrophic factor (BDNF) localization are shown here for the outer annulus (OA, $n=$ 22 ), the inner annulus ( $I A, n=6)$, and the nucleus (nuc, $n=4)$. The mean percentage in the $\mathrm{OA}$ is significantly greater than that present in IA or in nuc $(P \leq 0.01)$. Data presented as the mean \pm standard error of the mean. 
Figure 4

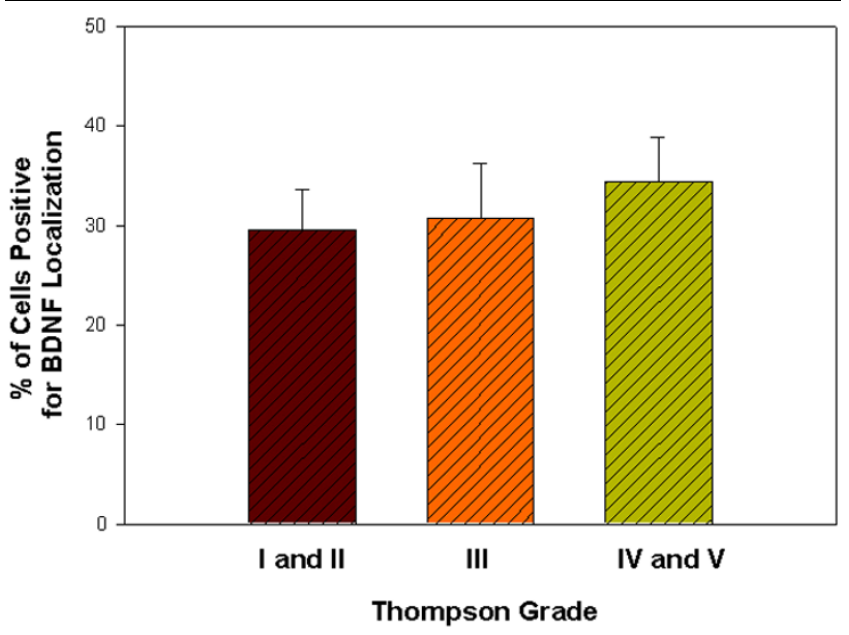

Outer annulus cells positive for brain-derived neurotrophic factor localization by Thompson grade. Mean percentage of outer annulus cells positive for brain-derived neurotrophic factor (BDNF) localization is shown for specimens from Thompson grades I and II pooled $(n=5)$, for grade III $(n=6)$, and for grades IV and V pooled $(n=11)$. Data presented as the mean \pm standard error of the mean.

Studies have recently shown production of several neurotrophins by IVD cells, but the mechanisms that control their expression, and the effects these factors have on disc cells, are poorly understood. Gigante and colleagues recently reported the presence of NGF mRNA and the high-affinity tyrosine kinase A receptor and the low-affinity p 75 receptor in the rounded cells in the disc annulus and nucleus pulposus [5]. The p75 receptor is of special interest because it also has the ability to bind to BDNF [20].

The work presented here adds to, and expands, our understanding of the distribution of BDNF and its receptor in the

\section{Figure 5}
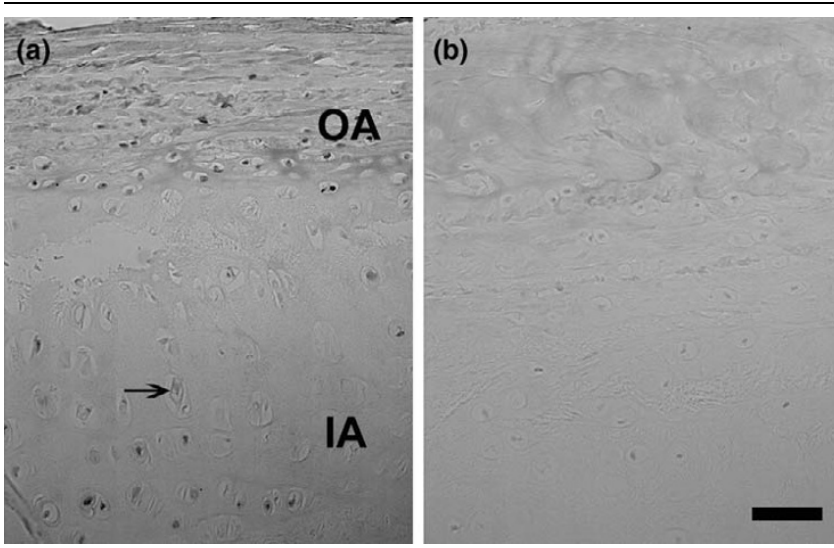

Immunolocalization of brain-derived neurotrophic factor in sand rat intervertebral discs. (a) Immunolocalization of brain-derived neurotrophic factor in a lumbar sand rat intervertebral disc. OA, outer annulus; IA, inner annulus; arrow, negative cell in the IA. (b) Negative control. Bars $=50 \mu \mathrm{m}$.
Figure 6

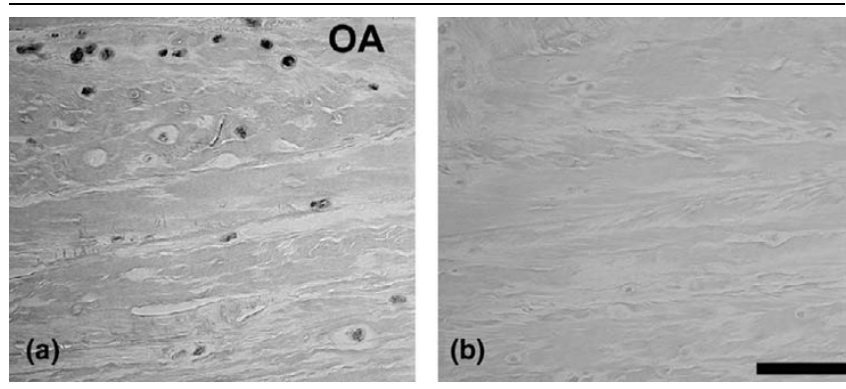

Immunolocalization of brain-derived neurotrophic factor receptor in human intervertebral discs. (a) Immunolocalization of brain-derived neurotrophic factor receptor in subject number 7, L4 to L5. OA, outer annulus. (b) Negative control. Bars $=50 \mu \mathrm{m}$.

human IVD. In addition to NGF, BDNF has recognized neuroprotective effects [21]. There is also evidence that BDNF can be considered a neurotransmitter and may have a role in nociceptive transmission [22]. Work by Thompson and colleagues suggests that BDNF may be released from primary sensory nociceptors with activity such as that involved with persistent pain states and inflammatory conditions [9]. It is well recognized that differential regulation of neurotrophin expression occurs in inflammatory states, such as in the airway, where NGF, BDNF and neurotrophin 3 have been shown to be elevated during inflammation [23]. Increased proinflammatory cytokines are now well recognized during IVD degeneration [24-27], providing support for the hypothesis that BDNF in vivo may be produced in response to inflammatory cytokines during IVD degeneration. Clearly the relationship of BDNF to inflammatory cytokines in the IVD merits future research attention.

The recent studies of by Kermani and colleagues regarding the ability of BDNF to promote revascularization via endothelial cells and hematopoietic progenitors are currently unexplored in the IVD [11]. These investigators suggest that the signaling pathway involving BDNF and its receptor may function in modulation of angiogenesis in specific organs in the adult. Since

\section{Figure 7}

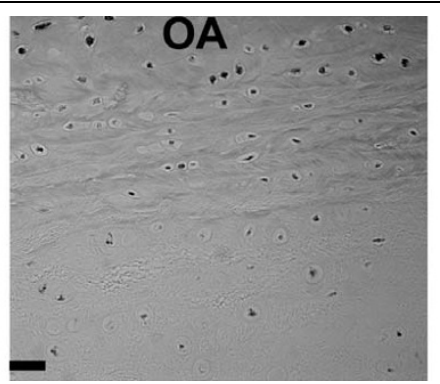

Immunolocalization of brain-derived neurotrophic factor receptor in sand rat intervertebral discs. Immunolocalization of brain-derived neurotrophic factor receptor in a lumbar sand rat intervertebral disc. OA, outer annulus. Bar $=25 \mu \mathrm{m}$. 
Figure 8

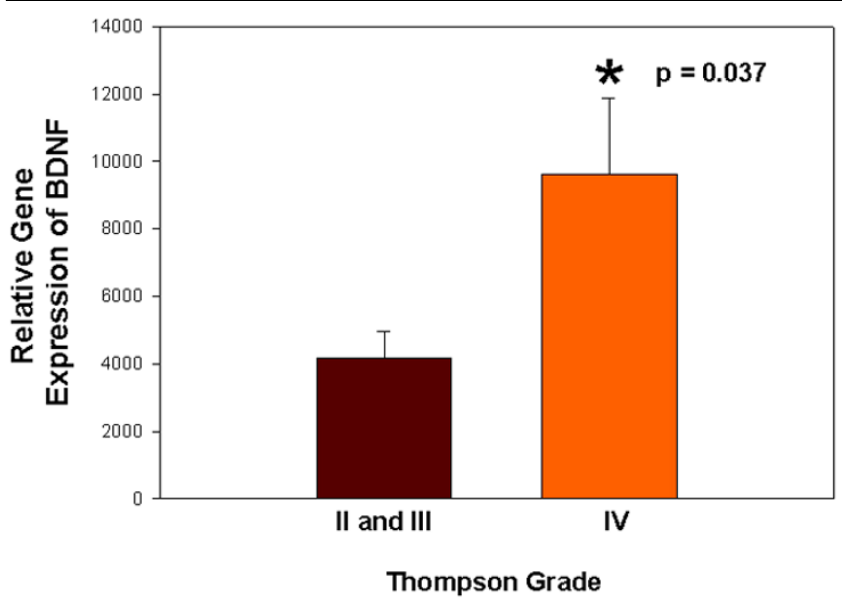

Gene expression levels of brain-derived neurotrophic factor in cultured human annulus cells versus Thompson grades. Graphical presentation of relative gene expression levels of brain-derived neurotrophic factor (BDNF) in cultured human annulus cells versus Thompson grades. Intervertebral discs of grades II and III were pooled $(n=6)$ and compared with intervertebral discs of grade IV $(n=5)$. Relative gene expression is significantly greater in the grade IV specimens $(P=$ $0.037)$. Data presented as the mean \pm standard error of the mean.

the adult disc is avascular, the potential of BDNF to influence angiogenesis in the mature disc is intriguing.

Finally, the initial observations by Boyd and colleagues that showed the upregulation of BDNF by application of increased osmolarity remains intriguing [1], and suggests the potential importance of the unexplored relationship between mechanoregulation and BDNF in the human IVD.

\section{Conclusion}

The data presented here document the presence of BDNF and its receptor in the human IVD at the translational level, and also show the expression of BDNF and its receptor by cultured human annulus cells. Quantitative assessment of the proportion of cells positive for BDNF localization showed that the outer annulus contained a significantly larger proportion of positive cells compared with the inner annulus or the nucleus $(P \leq 0.01)$. Our findings point to the need for further studies to define the role of BDNF in the human IVD and to investigate regulatory events, especially those related to mechanoregulation, which regulate the expression of BDNF and its receptor in the human IVD.

\section{Competing interests}

The authors declare that they have no competing interests.

\section{Authors' contributions}

HEG conceived of the study and participated in study design with $\mathrm{ENH}$, analyzed the data, and prepared and revised the manuscript. JAI, GH and NZ performed laboratory work and analysis. HJN performed statistical analyses and assisted with manuscript preparation. All authors approved the final manuscript.

\section{Acknowledgements}

The authors wish to thank the Brooks Center for Back Pain Research for its support.

\section{References}

1. Boyd LM, Richardson WJ, Chen J, Kraus VB, Tewari A, Setton LA: Osmalarity regulates gene expression in intervertebral disc cells determined by gene array and real-time quantitative RTPCR. Ann Biomed Eng 2005, 33:1071-1077.

2. McHugh JM, McHugh WB: Pain: neuroanatomy, chemical mediators, and clinical implications. AACN Clin Issues Adv Pract Acute Crit Care 2000, 11:168-178.

3. Sommer C, Kress M: Recent findings on how proinflammatory cytokines cause pain: peripheral mechanisms in inflammatory and neuropathic hyperalgesia. Neurosci Lett 2004, 361:184-187.

4. Bennett JH: Neurotrophic factors: important regulators of nociceptive function. Neuroscientist 2001, 7:13-17.

5. Gigante A, Bevilacqua C, Pagnotta A, Manzotti S, Toesca A Greco F: Expression of NGF, Trka and p75 in human cartilage. Eur J Histochem 2003, 47:339-344.

6. Mendell LM, Albers KM, Davis BM: Neurotrophins, nociceptors, and pain. Microsc Res Tech 1999, 45:252-261.

7. Abe Y, Akeda K, An HS, Aoki Y, Pichika R, Muehleman C, Kimura $T$, Masuda K: Proinflammatory cytokines stimulate the expression of nerve growth factor by human intervertebral disc cells. Spine 2007, 32:635-642.

8. Ohtori S, Takahashi K, Moriya H: Existence of brain-derived neurotrophic factor and vanilloid receptor subtype 1 immunoreactive sensory DRG neurons innervating L5/6 intervertebral discs in rats. J Orthoped Sci 2003, 8:84-87.

9. Thompson SWN, Bennett DLH, Kerr BJ, Bradbury EJ, McMahon SB: Brain-derived neurotrophic factor is an endogenous modulator of nociceptive responses in the spinal cord. Proc Natl Acad Sci USA 1999, 96:7714-7718.

10. Guo W, Robbins MT, Wei F, Zou S, Dubner R, Ren K: Supraspinal brain-derived neurotrophic factor signaling: a novel mechanism for descending pain facilitation. J Neurosci 2006, 26:126-137.

11. Kermani $P$, Rafii $D$, Jin $D K$, Whitlock $P$, Schaffer $W$, Chiang $A$, Vincent L, Friedrich M, Shido K, Hackett NR, Crystal RG, Rafii S, Hampstead BL: Neurotrophins promote revascularization by local recruitment of $\mathrm{TfkB}^{+}$endothelial cells and systemic mobilization of hematopoietic progenitors. J Clin Invest 2005, 115:653-663.

12. Thompson JP, Pearce RH, Schechter MT, Adams ME, Tsang IKY, Bishop PB: Preliminary evaluation of a scheme for grading the gross morphology of the human intervertebral disc. Spine 1990, 15:411-415.

13. Gruber HE, Johnson T, Norton HJ, Hanley EN Jr: The sand rat model for disc degeneration: radiologic characterization of age-related changes. Cross-sectional and prospective analyses. Spine 2002, 27:230-234.

14. Gruber HE, Johnson TL, Leslie K, Ingram JA, Martin D, Hoelscher G, Banks D, Pheiffer L, Coldham G, Hanley EN Jr: Autologous intervertebral disc cell implantation: a model using Psammomys obesus, the sand rat. Spine 2002, 27:1626-1633.

15. Gruber HE, Fisher EC Jr, Desai B, Stasky AA, Hoelscher G, Hanley EN: Human intervertebral disc cells from the annulus: threedimensional culture in agarose or alginate and responsiveness to TGF- $\beta 1$. Exp Cell Res 1997, 235:13-21.

16. Gruber HE, Hoelscher GL, Leslie K, Ingram JA, Hanley EN Jr: Three-dimensional culture of human disc cells within agarose or a collagen sponge: assessment of proteoglycan production. Biomaterials 2006, 27:371-376.

17. Aoki Y, Ohtori S, Takahashi K, Ino H, Takahashi Y, Chiba T, Moriya $\mathrm{H}$ : Innervation of the lumbar intervertebral disc by nerve growth factor-dependent neurons related to inflammatory pain. Spine 2004, 29:1077-1081.

18. Aoki Y, Takahashi Y, Ohtori S, Moriya H, Takahashi K: Distribution and immunocytochemical characterization of dorsal root gan- 
glion neurons innervating the lumbar intervertebral disc in rats: a review. Life Sci 2004, 74:2627-2642.

19. Freemont $A J$, Watkins $A$, LeMaitre $C$, Baird $P$, Jeziorska $M$, Knight MTN, Ross ERS, O'Brien JP, Hoyland JA: Nerve growth factor expression and innervation of the painful intervertebral disc. $J$ Pathology 2002, 197:286-292.

20. Pagnotta A, Tos P, Fornaro M, Gigante A, Geuna S, Battiston B: Neurotrophins and their receptors in early axonal regeneration along muscle-vein-combined grafts. Microsurgery 2002, 22:300-303.

21. Nakazawa T, Tamai M, Mori N: Brain-derived neurotrophic factor prevents axotomized retinal ganglion cell death through MAPK and P13K signaling pathways. Invest Ophthalmol Vis Sci 2002, 43:3319-3326.

22. Pezet S, Malcangio M, McMahon SB: BDNF: a neuromodulator in nociceptive pathways? Brain Res Rev 2007, 40:240-249.

23. Kemi C, Grunewald J, Eklund A, Höglund CO: Differential regulation of neurotrophin expression in human bronchial smooth muscles. Respir Res 2006, 7:18.

24. LeMaitre CL, Hoyland JA, Freemont AJ: Catabolic cytokine expression in degenerate and herniated human intervertebral discs: IL-1 $\beta$ and TNF $\alpha$ expression profile. Arthritis Res Ther 2007, 9:R77.

25. Kang JD, Georgescu HI, McIntyre-Larkin L, Stefanovic-Racic M, Evans $\mathrm{CH}$ : Herniated cervical intervertebral discs spontaneously produce matrix metalloproteinases, nitric oxide, interleukin-6, and prostaglandin $\mathrm{E}_{2}$. Spine 1995, 20:2373-2378.

26. Kang JD, Georgescu HI, Mclntyre-Larkin L, Stefanovic-Racic M, Donaldson WF III, Evans $\mathrm{CH}$ : Herniated lumbar intervertebral discs spontaneously produce matrix metalloproteinases, nitric oxide, interleukin-6, and prostaglandin $E_{2}$. Spine 1996, 21:271-277.

27. LeMaitre CL, Freemont AJ, Hoyland JA: The role of interleukin-1 in the pathogenesis of human intervertebral disc degeneration. Arthritis Res Ther 2005, 7:R732-R745. 